\title{
THE DETERIORATION OF REFRACTORY MATERIALS IN THE IRON AND STEEL INDUSTRIES.
}

The following Papers on "The Deterioration of Refractory Materials in the Iron and Steel Industries," and "The Standardization of Refractory Materials used in the Iron and Steel Industries," by Professor H. B. Cronshaw, B.A., Ph.D., A.R.S.M. (University College, Galway), were communicated to the Society after the meeting.

The following discussion is an outcome of an attempt made to trace the agents concerned in the destruction of the refractory portions of furnaces used in the iron and steel industries, and the manner in which this destruction takes place, by actual examination of the furnaces themselves, and by the application of petrographical methods involving the use of the high-power microscope. It is intended here to record only the main outlines of the work. For additional details concerning refractory materials used in the iron and steel industries, reference may be made to two papers by the author, included in the bibliography given at the end of the present one.

In view of the recent awakening of interest in all that concerns the manufacture and utilization of refractory materials, it is almost superfluous to direct attention once again to the vital importance of formulating standard specifications. Nor is it necessary to point out the vast field of research which still remains to be covered, and the great possibilities which underlie the application of petrographical methods and of the principles of mineralogy, with especial reference to recent work on the behaviour of minerals and mixtures of minerals at high temperatures. Although this applies generally to all metallurgical industries in which refractory materials are made use of, it assumes a special importance in the case of the iron and steel industries. This is not surprising when one considers the excessive demands made upon the refractory linings of iron- and steel-making furnaces of every description. Working conditions are becoming more severe and efforts are continually being made to economize in working expenses, and hence arises the necessity for a corresponding advance in the manufacture of firebricks. The extent to which this has been carried out can best be judged by the consumer himself. Whatever the opinion may be, there can be no doubt that, as matters stand at present, the refractory linings in all types of iron and steel furnaces undergo far too rapid destruction, especially in particular parts of certain furnaces. The effects of this on the total working costs are sufficiently obvious, so that this consideration alone would justify any attempted investigation into the reasons for this excessive rate of deterioration.

It is clear that, whatever the destructive agents may be, they must vary in nature and intensity according to the type of furnace and the particular part of it under consideration. In other words, each part of every refractory lining is exposed to attacks from certain definite destructive agents of a chemical and physical nature, so that the wear and tear is by no means uniform and entirely due to one cause alone. Thus, for the bricks to 


\section{DETERIORATION OF REFRACTORY MATERIALS}

efficiently withstand these influences, they must be endowed with special chemical and physical qualities, and before these required qualities can be specified by the consumer for any part of his furnace-lining he must be fully acquainted with the adverse conditions which prevail at that point. And so it is for each part of every type of furnace; the first step towards supplying a lining is to ascertain the destructive forces at work in every part of it, as well as the rate and manner in which the destruction takes place.

\section{OPEN-HEARTH FurNaces.}

Construction.-The nature and arrangement of the bricks used in constructing the lining of an open-hearth furnace vary, of course, to some extent according to local practice. The variation is, however, not very great, and examples may be cited as illustrative of general practice.

In the case of a typical furnace of the acid type, silica bricks are used for the roof, sides, and blocks. The hearth consists of numerous layers of fritted sand, banked up to the doors and resting upon a stepped arrangement of silica bricks. For the main portion of the blocks an inferior type of brick is often employed. In one particular instance the roof measured 9 in. in thickness, the sides 18 in., whilst the bottom comprised 6 in. of silica bricks and 15 in. of fritted sand.

In modern basic furnaces magnesia bricks are employed in the construction of the bottom, ends, gas-ports, the back wall to within four courses of the roof, and for the front wall up to the springing of the arches. The roof, together with portions of the walls and blocks, are built of silica bricks, whilst the doors are faced with ganister bricks on the inside and ordinary frebricks on the outside. The hearth consists of a mixture of dolomite and tar. For further protecticn most modern furnaces are furnished with a system of water-cooled pipes passing round the doors, the ports, and the junction between the movable blocks and body of the furnace. In ordinary cases the sides measure $2 \mathrm{ft}$. in thickness, the roof $18 \mathrm{in}$. at the centre and I 2 in. near the ends, the dolomite hearth 12 in., and the magnesia bottom $2 \mathrm{ft}$. Such an arrangement with these measurements would apply, for instance, to a I50-ton Talbot furnace of recent design.

Destruction.-Furnaces of the acid type described above were stopped each Saturday at noon, so that any necessary repairs to the lining could be carried out during the afternoon. This discontinuance of operations, and the cooling down of the furnace, together with the employment of skilled labour working under very adverse conditions, is an extremely serious matter and an obvious source of considerable expense and loss of time. Firing was not resumed until 3 o'clock on Sunday morning, and at about 7 o'clock the furnaces received their first charge of cold pig iron. Furnaces of this type, without slag-pockets, usually survive some I9 weeks, or 144 heats, before being stopped for serious repairs, or partial rebuilding, which may consist in the erection of a new roof and sides. With slag-pockets, however, this brief term may be lengthened to some 22 weeks, or about 198 heats.

In the case of modern basic furnaces, repairs are carried out at the end of every heat by the aid of chromite mortar, especially near the doors, which is of course an expensive operation. Furthermore, on Saturday afternoon the gas has to be cut off, the blocks clrawn back, and all faulty places repaired under the same trying conditions mentioned above. For the blocks ganister mortar is used, near the water-pipes and in the body of the furnace chromite is employed, while crushed dolomite is thrown upon the hearth. At the end 
of about 18 weeks the roof may be reduced from 12 or 18 in. to some 2 or 3 in. in thickness, and this, together with the front wall, usually requires rebuilding. The back wall is, however, not so easily destroyed, for at the end of this period it may vary from about 9 in. in thickness at the upper parts to about I 8 in. where it meets the hearth, and can consequently be repaired without the necessity of total reconstruction.

Roof.-If the interior of a furnace is examined, when cooled down for repairs, the inner surface of the roof will be found irregularly eroded into hollows and grooves. Fissures run in various directions, and holes occur where portions of the bricks have fallen away. In certain places the surface presents an embossed appearance, with the depressions coinciding with the joints between the bricks. Everywhere the exposed surfaces are glazed and darkened in colour, so that the most casual observation points to important changes in texture and composition. The extent of this erosion is by no means uniform over the whole roof. In the central portions, above the middle door, a greater general depression occurs than elsewhere. Towards either end of the furnace the furrows frequently show a definite arrangement, spreading out fanwise from the air-ports. In the case of furnaces having airports at the upper corners of the end walls, the roof is traversed at either extremity by two longitudinal hollows separated by an intervening ridge. This curious arrangement of grooves evidently points to either the influence of abrasion or to fusion by contact with the flames along certain lines determined by the inflowing currents. No definite evidence is at hand by which a choice can be made between these two factors. Very probably both take a share in the work, as both are certainly active in these regions. Particles of dust which have accumulated upon the upper surfaces of the regenerator chequer-bricks are swept into the body of the furnace by the incoming air and producer-gas. Impelled upon the roof they must, in the course of time, effect abrasion much in the same manner as the familiar sand-blast. The intensity of this bombardment will fall off as the particles penetrate farther into the interior of the furnace, on account of decreasing velocity and their probable fusion. That the "cutting action" of the flames is a matter of practical importance is shown by the steps taken to prevent, as far as possible, any actual contact with the roof. In the central portions of the roof the rate of erosion reaches a maximum. Here the bricks, which frequently crack and break away, experience rapid changes in temperature, due to the opening and closing of the doors and the introduction of cold charges. This results in differential movements between both the constituent particles of the bricks and the bricks themselves, so that the strains set up are occasionally relieved by fissuring and general disintegration. Thus, although abrasion and differential movements certainly do take some share in the general deterioration of the brickwork, their importance as self-contained denuding agents in normal cases must not be overestimated. Thus in one particular instance a trial was made with "non-expansible" bricks in the roof of a furnace with unsatisfactory results ; erosion proceeded much the same way as before. Rather must these physical agents be looked upon as assisting another and much more potent factor, that of fluxation.

The inner surface of the roof in its fused and sticky condition retains all dust particles swept against it. This dust, consisting chiefly of ferric oxide and lime, is derived from regenerators, producers, material charged into the furnace, and the occasional violent spurting of the bath of molten slag and iron. In addition there is the action of certain compounds in a volatilized condition. It is important to note that the central portions of the roof, where denudation is greatest, are most exposed to the lime and ferric oxide of the 


\section{DE'TERIORATION OF REFRACTORY MATERIALS}

charges. Thus all basic dust and volatilized products which are brought into contact with the silicious roof combine to aid in a general process of fluxation. Whenever cracks are present, whether large or microscopic, the fluxing action is somewhat assisted owing to the penetration of dust, vapours, and small quantities of slag into the interiors of the bricks. Evidence of this is to be found in the frequent embossed appearance of portions of the roof, brought about by more rapid erosion along lines of the joints. In the absence of cracks the slag resulting from this surface fluxation of the roof seems unable to penetrate of its own accord into the interior of the bricks, which means that porosity and permeability are of less moment than one might at first sight suppose. As soon as a certain quantity of slag has accumulated it is doubtless swept away by the inrush of the gases. That this failure of the slag to permeate through the body of the bricks is actually the case can be seen by examination of a brick taken from the roof of a furnace after completing its usual term of life.

A typical example of such a brick is represented in Fig. I, which is a photograph of a high-class silica brick taken from the central portion of the roof of a I50-ton Talbot furnace after a period of 18 weeks. As regards texture, colour, and general appearance, four zones, A, B, C, and $D$, are plainly distinguishable, and the end, $A$, was the one exposed at the inner surface of the roof. In the photograph the black edge represents the fused and slaggy portion, which on its inner surface is clearly seen to be sharply marked off from the interior. At $\mathrm{A}$ is a light-grey, porous, and somewhat friable band about $I$ in. in width, and this is followed by a black zone, about 2 in. in width, containing a few fragments of white grog, but very similar in texture to $\mathrm{A}$. This passes more or less abruptly into the section $\mathrm{C}$, which is very dark olive-green in colour, and crowded with angular pieces of grog. Lastly there is a narrow strip of comparatively unaltered material, represented by the band $D$.

Fragments were removed from each of these four zones and made into thin transparent sections by the usual petrographical methods for detailed examination under the microscope. A section cut from an unused brick of the same kind shows angular fragments of grog embedded in a brownish coloured groundmass; see Fig. 2. Under a high power the grog resolves itself into a mosaic of small, subangular particles of quartz, closely packed together and enclosing numbers of minute bubbles. They are fairly uniform in size, and are separated from one another by films of what appears to be chiefly oxide of iron. On the other hand, the groundmass consists of generally larger individuals of quartz, varying considerably in size, and embedded in an unresolvable brownish matrix of oxide of iron and lime. In the partly altered portion, D, at the upper end of the used brick, the grog, apart from the formation of small amounts of glass between the fragments of quartz, remains in a practically unaltered condition. The groundmass, however, is completely changed. The irregular fragments of quartz have disappeared, and in their place are minute well-shaped crystals, apparently of the same mineral, embedded in a brownish glass. In $\mathrm{C}$ the grog is still unaffected, but the crystals of the groundmass have become somewhat larger, more transparent, and more sharply outlined. In B (see Fig. 3), the material of the grog has suddenly become transformed into a brown, glassy matrix crowded with extremely minute crystals of quart\%. Furthermore, the crystals in the groundmass have grown considerably into clear, well-formed individuals, which show undulating extinction and give anomalous interference colours, and the brown, glassy matrix has developed skeleton crystals of microscopic size. Within the last and most altered zone, A 


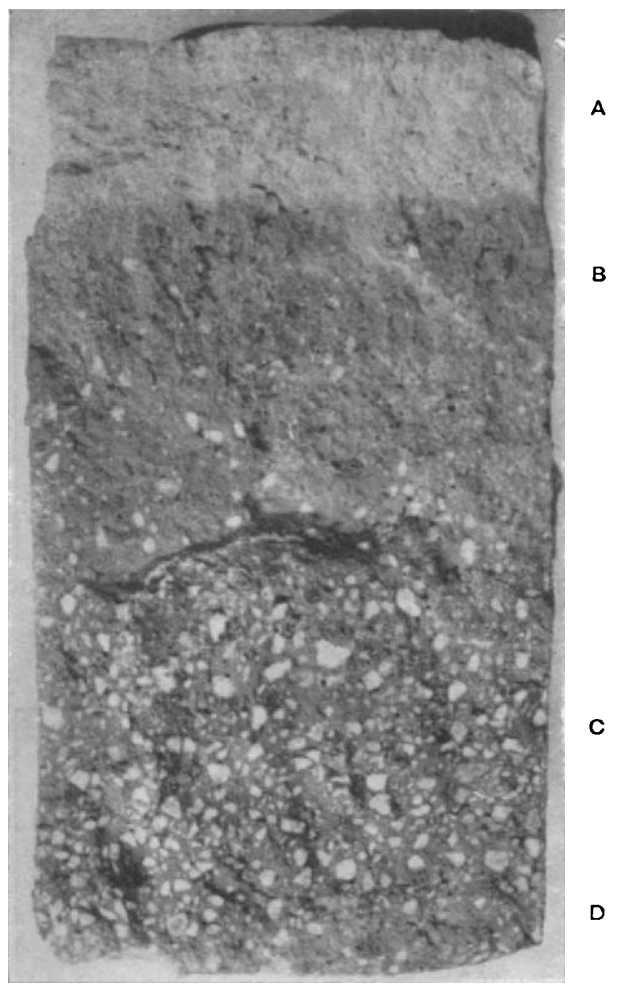

FIG. I.-Silica brick from the roof of a I 50 -ton Talbot furnace aiter I 8 weeks' use. Reduced to about one-third natural size

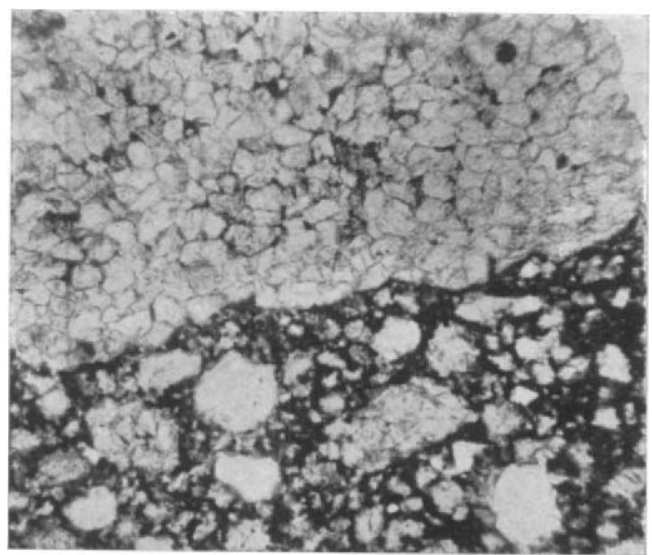

FIG. 2.-Unused silica brick for roof of an open-hearth furnace. Shows part of a grog fragment embedded in the darker groundnass. 


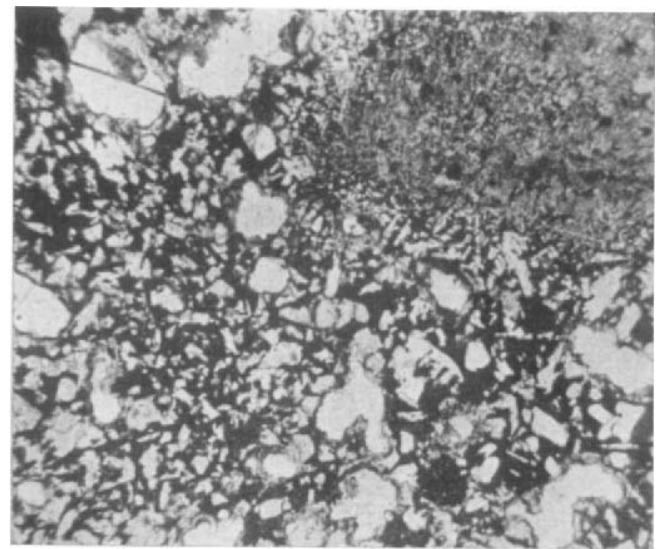

Fir. 3.- Section from the centre of the same brick after use. The fine-grained patch represents an altered grog fragment.

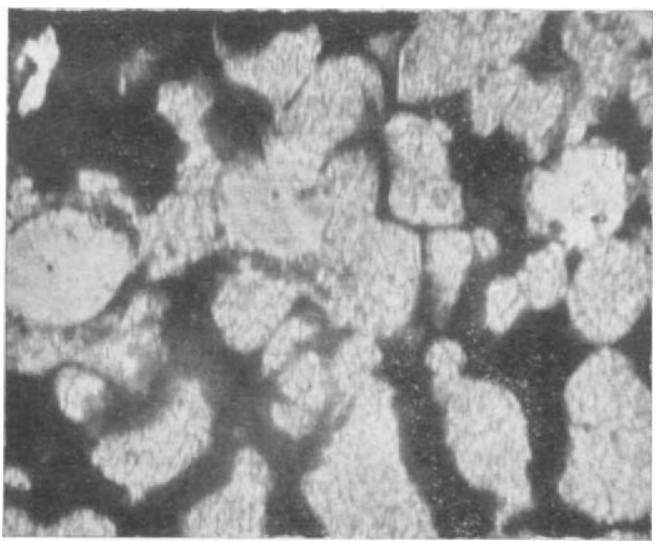

FIG 4.-A section of the same brick taken near the exposed surface, showing aggregates of overlapping scales of tridymite.

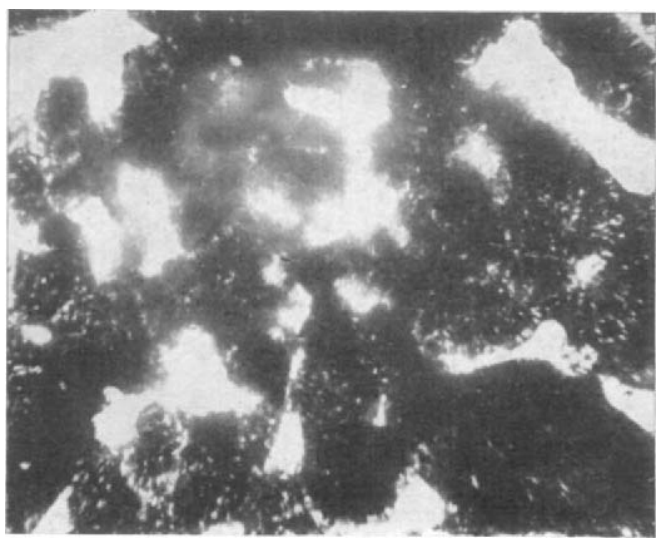

FIG 5-- Section of an unused magnesia brick, illustrating the relation between pore-spaces and groundmass. 


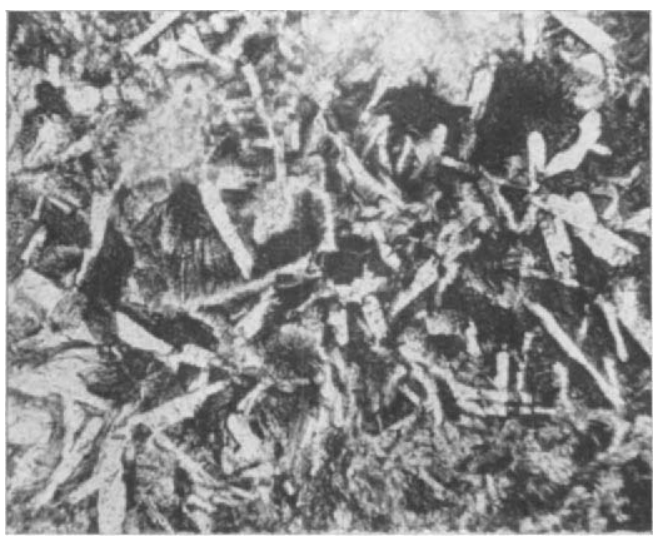

FIG. 6.-Section of fused surface of a silica brick taken from the block of an open hearth furnace. Shows acicular crystals embedded in a glassy groundmass. The two light patches are remnants of grog.

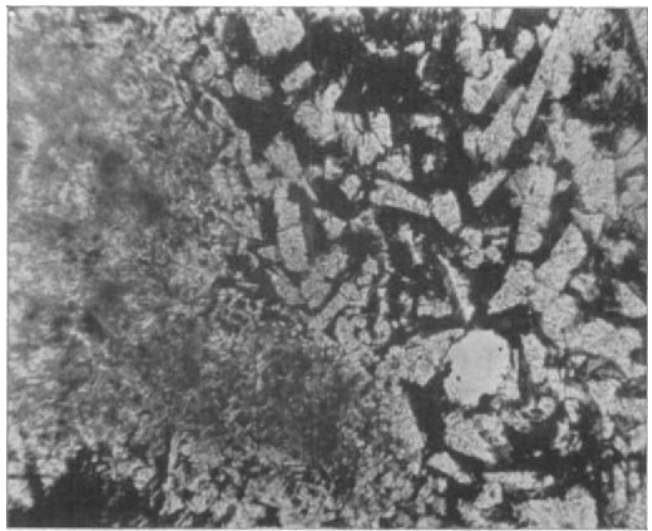

FIG. 7.--Section from centre of brick taken from the block of an open-hearth furnace. The fine-grained patch represents a grog fragment. 
(see Fig. 4), a further change has resulted in the conversion of crystals in both grog and groundmass into a mosaic of overlapping and roughly hexagonal scales, arranged like tiles on a roof, and having a very low birefringence and index of refraction. These scales appear to represent the polymorphous modification of quartz, viz. tridymite. In spite of this change, the original crystals have retained their partly hexagonal outlines, although in substance completely replaced by the tridymite. Between these clear, scaly aggregates is a yellow-brown glass crowded with brownish coloured skeleton crystals. As regards the outermost and fused margin, which contains very many skeleton crystals of magnetite, chemical analysis showed an increase in content of oxide of iron and lime when compared with unaltered portions.

Sides.-With silica brick walls destruction proceeds very much in the same way as in the roof. The action of slag is, however, somewhat different, in that it creeps down the walls and tends to accumulate near the bottom. As a result the slag is given a better opportunity of penetrating into the brickwork by means of cracks and fissures.

In cases where the walls are constructed of magnesia bricks, chemical activity is much reduced. Here the chief cause of destruction seems to arise from shrinkage of the exposed ends of the bricks, thus opening up fissures along the joints. This shrinkage in magnesia bricks is often considerable, as can be seen by examination of any furnace. Generally there is slagging, and the only other obvious changes are to be found in decrease of porosity and a darkening in colour. Fig. 5 represents a photomicrograph of an unused magnesia brick and illustrates their extremely porous nature.

Port-blocks.-Although here the temperatures are lower-about $\mathrm{I}, \mathrm{IOO}^{\circ} \mathrm{C}$ - than in the actual body of the furnace, yet the exposed brickwork comes more directly under the fluxing influence of the dust. Examination of the passages when the blocks are drawn back, shows clearly that there must be a constant creep of slag down the walls. Bricks taken from the blocks frequently show the banding observed in roof-bricks, though not so clearly marked.

A micro-section of the fused surface of a silica brick (see Fig. 6), taken from the air-flue in the block of a Talbot furnace, shows numerous crystals with a low birefringence and straight extinction, embedded in a greenish-yellow glass. Where free to develop they have formed needleshaped individuals without definite terminations, but where more crowded together they are stumpy. Basal cleavage-cracks are well developed.

Another section (see Fig. 7) of the centre of a silica brick taken from the block of a Siemens basic furnace shows the same general features as the last, except that the matrix is crowded with skeleton crystals of magnetite and the outlines of grog fragments are preserved. The interiors of the grog fragments are occupied by glass containing a few small remnants of the original quartz grains, thus representing the final stages of solution.

Conclusions. - Within the body of the furnace and along the sides of the passages through the blocks, the main cause of deterioration is apparently to be sought in the slagging effects of, firstly, the basic dust derived principally from the charges, but also to some extent from the regenerators and producers, and, secondly, the particles of slag shot up from the melt at times of violent ebullition and the vaporized compounds derived from various sources. There are other factors which come into play, helping these chemical processes to an extent depending on the particular part of the furnace under consideration. At the end portions of the roof excessively high temperatures, abrasive

VOL. XII. PARTS I, 2, AND 3 . 
action, and the sweeping away of any accumulated slag to expose fresh surfaces for fluxation, are the predominant physical influences at work. In the central parts of the roof, where rapid changes in temperature result from frequent opening and closing of the doors and the introduction of cold charges, differential movements and strains in the brickwork are relieved by fissuring and a falling away of large and small fragments. It is probable that fissuring alone is not important in absence of accumulated slag, but the breaking away of portions of the bricks will expose fresh surfaces for attack by chemical agencies. In this region, also, fluxation proceeds most rapidly on account of the repeated supply of basic dust from the charges.

In the case of silicious walls, the presence of fissures will facilitate the penetration of slag, and hence promote internal fluxation. When magnesia, chromite, and similar materials are employed, chemical activity is reduced and deterioration practically entirely results from shrinkage. At least this is so in the case of magnesia, which finds general use at the present day for parts of the walls.

Within the passages through the blocks the temperature is lower, but the dust, being confined within less space, is brought more intimately into contact with the exposed surfaces. Physical and chemical processes are both active, and a good deal of slag is formed. At the ports destruction proceeds more rapidly, mainly on account of the high temperatures which prevail there.

\section{REgENERATORS.}

Most regenerators are built on the same general plan, and practically all modern types are fitted with slag-pockets. For construction of the chequer-work ganister bricks are in common use.

The gas-chambers of regenerators attached to large Talbot furnaces last about 18 months before the chequer-work requires replacing. In the case of the air-chambers this period is reduced to some 12 months. During this time, however, the chambers are frequently opened up for general cleaning and removal of as many broken and fluxed bricks as possible. For instance, the regenerators attached to a certain 150-ton Talbot furnace had to be opened only $14 \frac{1}{2}$ weeks after the installation of new chequer-works. Even after this brief use, a considerable amount of destruction had taken place in a manner which is described below. In other cases, where basic Siemens furnaces with slag-pockets were in use, the gas-chambers were run for about two years and the air-chambers about one year before being rebuilt. On the other hand, both gas- and air-chambers attached to a set of acid Siemens furnaces, with slag-pockets, were only allowed some 40 weeks of active life. The installation of slag-pockets always has the effect of prolonging the lives of regenerators, and the quantity of slag which accumulates is remarkable, amounting, in the particular case of a small basic Siemens furnace, to a depth of about a foot per month. It is obvious, therefore, that the term of life which can be allotted to generators is a somewhat variable quantity. As all regenerators are built on the same general plan, it will largely depend on the type of furnace and the adopted practice.

Examination of the chequer-work in the case of the r5o-ton Talbot furnace cited above showed that the upper surfaces of the bricks were thickly covered with chocolate-brown dust, which had fused at its contact with the bricks. This gave rise to a dark-coloured viscous slag, which had run over the sides of the bricks and collected in stalactites on their under surfaces. There was clear evidence of a dripping of this slag, from brick to 
brick, through the whole chequer-work. At this early stage the bricks were not greatly altered; some were cracked and had to be removed, but the majority appeared to be fairly sound. On comparing the effects in air- and gas-regenerators, it was evident that in the former there was a greater amount of slag, and here, too, the chequer-bricks showed more obvious signs of general destruction. The central portions of the bricks were yellowish in colour, whilst the marginal portions were bleached, but apart from surface fusion the general texture remained much the same as originally. Within the gas-chamber there appeared to be quite as much dust, but fusion and slag formation had gone on to a considerably less extent. The colour of the fractured surfaces of the chequer-bricks was also different, being grey instead of yellow. In the case of regenerators which have been in use for longer periods than this, the effects of fluxation are, of course, much more striking. A particular instance in which the air-chambers had been in operation about a year, and the gas-chambers had been allowed to run on for the space of two years, will serve to illustrate this point, and the furnace to which they were attached was a small type of basic Siemens furnace, provided with slag-pockets. The chequer-bricks were very considerably reduced in size-in many cases to less than half their original dimensions. They were black in colour, and penetrated by numerous holes and fissures, and were fused practically entirely throughout. Generally their upper surfaces were somewhat depressed, whilst the under surfaces had assumed a convex form.

Analysis of the dust which collects upon the chequer-bricks shows that it principally consists of ferric oxide and lime, with a certain amount of silica and magnesia. The following is an analysis of chequer-dust taken after I $4 \frac{1}{2}$ weeks from the gas-chamber of a large Talbot furnace :-

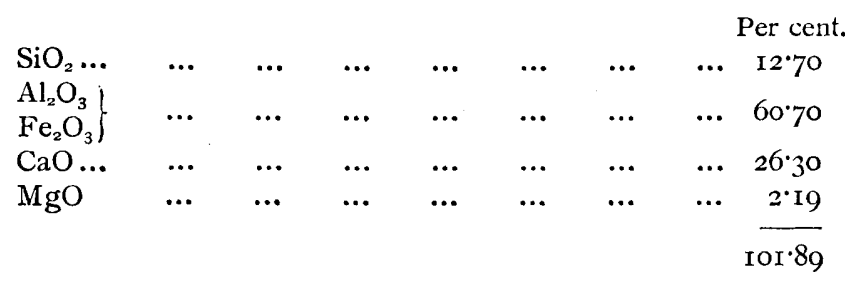

From this and other considerations there is no doubt but that the oxide of iron and the lime are derived from the charges, whilst the magnesia comes from the dolomite thrown upon the hearth when undergoing repairs. The main portion of the silica and alumina is doubtless derived from the fine particles of slag swept over from the furnace roof, from the surface of the melt during violent ebullition, and from the ash brought in by the producer-gases. When a basic dust such as this settles upon the white-hot surfaces of silicious bricks, the results are quite obvious. The destructive effects are further accentuated by the accumulation of the slag upon the upper surfaces of the bricks, so that the existence either of cracks or of a high degree of permeability becomes an important factor-much more so than in the case of the furnace-lining.

Micro-sections prepared from the surface of a brick taken from the chequer-work of an air-chamber after a period of one year showed fragments of grog, with their quartz grains still preserved, embedded in a brownish glassy groundmass crowded with extremely minute lath-shaped crystals having a very low index of refraction and birefringence. Both are 


\section{DETERIORATION OF REFRACTORY MATERIALS}

lower than those for quartz appearing in the same section. In the case of a slice taken from the interior of a chequer-brick belonging to the gaschamber, and after a period of two years' use, the same features as described above were presented, except that all traces of original quartz had disappeared.

Thus the deterioration of the regenerator bricks is mainly of a chemical nature, and is to be attributed to the fluxing influence of basic dust, derived principally from the charges, but partly also from the producers and from slag carried over from the body of the furnace. Furthermore, this fluxing action is very materially assisted by the development of cracks within the bricks, and by the existence of any degree of permeability, owing to the fact that the slag is allowed to collect upon the upper surfaces of these bricks. The slagging is also accumulative in the sense that any overflow drips from brick to brick through the chequer-work. The difference in terms of life between gas- and air-chambers is a further indication of the important part played by chemical influences.

\section{Blast-Furnaces.}

Above the bosh the lining is generally constructed of common firebricks, but within the bosh and hearth the same bricks are faced on the inside with high-grade firebricks. The term of life allotted to a blast-furnace lining varies considerably in different cases, depending to a very large extent on the particular practice adopted.

Deterioration of the brickwork proceeds in a variety of ways, and the influences vary in nature and intensity from point to point within the furnace. A very good idea of the general results can be gained from the consideration of a lining which, at the time of examination, was being replaced after some thirty-eight years' continuous service. Within that portion of the shaft between the top of the bosh and a point some $13 \mathrm{ft}$. below the top of the furnace, a thickness of about $2 \frac{1}{4} \mathrm{ft}$. of brickwork had been removed by denuding influences. Within the bosh, however, the lining retained its original thickness, but was to a large extent replaced by carbonaceous matter, to form the black, porous, and somewhat friable "scar." This "scar" first appeared at a depth of about $28 \mathrm{ft}$., and increased in thickness when followed into the bosh. Traced into the walls, it gradually died out and gave place to the outer layers of brickwork, which, apart from fissuring and cracking, showed remarkably little evidence of alteration. There were no signs of fluxation or fusion. Deposited within the fissures, pores, and crevices between the various layers of brickwork were numerous small yellow hexagonal crystals of zincite, containing 99 per cent. of zinc oxide and I per cent. of lead oxide. In addition to these, other minerals occurred, both within the outer layers of "scar" and within the unaltered brickwork. Such, for example, were deposits of soda, potash, and chlorides of soditum and ammonium. The zincite is said to have first made its appearance, in abundance, at a depth of about $35 \mathrm{ft}$. below the top of the furnace, whilst at various points below a depth of $20 \mathrm{ft}$. a good deal of white, powdery, and deliquescent zinc chloride was found by those engaged in pulling down the lining.

Fram these and other considerations one can form an opinion as to the extent to which the several destructive processes are operative in the different sections of the furnace. Near the top of the furnace, where temperatures and chemical activity are lowest, the brickwork comes under the abrasive influence of material charged into the furnace. That these effects of impact 
and abrasion are considerable can be gathered from the frequent use of castiron "wearing-rings."

Within the shaft the deterioration reaches a maximum, and forms the chief reason for the blowing-out of the majority of blast-furnaces. As pointed out above, the inner and more exposed parts of the shaft-brickwork become progressively replaced by the carbonaceous "scar," and the process of replacement can be clearly followed by the study of micro-sections cut from unused bricks and various parts of the "scar" and partially modified bricks. Sections of unused bricks show that the finely divided groundmass of quartz grains and argillaceous material is crowded with minute particles of iron oxide. To some extent they are also enclosed in the quartz grains of the grog. Approaching the "scar" the bricks assume a peculiar bluish-black colour, which deepens along with a change in texture, until within the "scar" itself all traces of the original texture and form of the bricks have disappeared, leaving a black, scoriaceous material, in which the small cavities are filled and lined with graphite. Micro-sections of the partly altered and bluish-black bricks show fragments of quartz enclosed in a groundmass crowded with carbonaceous dust, but within the inner portions of the "scar" itself all traces of the original quartz have disappeared; there is no argillaceous matter or oxide of iron, but instead dense aggregates of finely divided carbon contained in a matrix of overlapping, hexagonal scales of tridymite. Graphite can be seen filling or lining the numerous small cavities. The "scar" is relatively friable, and thus easily succumbs to abrasive action and local scaffolding. On the other hand, it protects the external layers of unaltered brickwork from the direct influence of heat and fluxes, but, doing so, permits the deposition of those various types of minerals mentioned above, which, besides assisting in the general process of crumbling and fissuring, constitute a source of danger in the event of local overheating. On such occasions the temperature may rise high enough to promote interaction between the bricks and deposited compounds with, for instance, the formation of alkaline silicates, so that fluxation would result and possibly give rise to local heat-spots. In one sense therefore the "scar" is protective, and in another destructive. It protects the relatively unaltered brickwork from the high temperatures and chemical activity of the charges, but at the same time it gives rise to conditions which favour the deposition of volatile compounds, locally capable of bringing about serious destruction of the lining, and moreover constitutes in itself a source of progressive and effective destruction, arising from its relatively friable nature.

Within the bosh high temperatures and chemical activity predominate, whilst the influence of abrasion and scaffolding hardly makes itself felt. In this region the formation of "scar" takes place to a greater extent than elsewhere, but in absence of serious abrasive action its influence is protective rather than destructive.

Chemical activity at high temperatures becomes an important feature in the hearth, and here, below the level of the melt, the presence of any fissures would lead to internal fluxation and a tendency to disruption of the brickwork on penetration of the molten iron or slag. By using cooling devices chemical activity is diminished, and probably a layer of solid or partly solidified slag or iron is formed against the lining.

\section{Cupolas.}

Although cupolas vary considerably in constructional details and actual working conditions, yet as regards general considerations dealing with deterioration of the linings, very much the same features must be presented 


\section{DETERIORATION OF REFRACTORY MATERIALS}

by all types. For this reason attention may be confined to a single example as illustrating conditions which generally prevail.

In this particular furnace, which is one of modern design, the interior was lined throughout with "best" firebricks to the extent of about 9 in. in thickness in the hearth and some $4 \frac{1}{2} \mathrm{in}$. in the shaft. The working period extended from 5 a.m. to 5 p.m., during which time tapping was carried on at frequent intervals. The probable temperature of the metal during tapping was somewhere in the neighbourhood of $1,200^{\circ} \mathrm{C}$., whilst within the melting zone the temperature varied between, say, $r, 400^{\circ} \mathrm{C}$. and $\mathrm{r}, 800^{\circ} \mathrm{C}$. The hearth and bosh required total relining every six to nine months, whilst the shaft survived two or three years. Fettling with ganister mortar had to be carried out every day, and also during the week-ends.

In general it may be said that cupola linings come under very much the same set of chemical and physical influences as blast-furnace linings. With regard to this particular furnace, however, there are several additional features of some importance which might be noted here. Within the shaft a good deal of the wear and tear could be attributed to the striking of lumps of pig and scrap iron against the sides during charging operations. In the bosh "scars" of iron, formed by local cooling due to the incoming blast, may cling to the sides, so that their subsequent removal is attended by serious damage to the brickwork.

Within the hearth the same trouble arises by the clinging of the slag to the sides during tapping. Another source of danger lies in the creation of oxidizing conditions, due to the use of insufficient coke or too much blast, resulting in the formation of iron oxide, capable of immediately fluxing any silicious material at hand.

\section{Conclusions.}

It appears, therefore, that in the case of open-hearth furnaces and their regenerators the main cause of deterioration is to be found in the fluxing influence of basic dust and volatilized compounds derived from various sources, but chiefly from the charges. Theoretically speaking the most obvious way of overcoming these difficulties is either to prevent any dust entering the furnace from both producers and charges, or else to suppress the dust before it can come in contact with the brickwork, or a third way would be to so adjust the composition of the bricks as to be neutral towards the agents in question. The first of these presents many practical difficulties, although there are several ways in which it might be carried out. However, if the whole of the fine dust cannot be removed on a large scale, nor its formation prevented during charging, there is no reason why care should not be taken to keep its amount as low as possible, for even this is certain to be attended by favourable results. The second way applies more particularly to regenerators, and an arrangement has been devised for eliminating the dust before it reaches the chequer-work. The third suggestion opens up a wide field for investigation. It seems highly probable that future research will point out a way of utilizing our natural deposits of basic minerals and rocks for the purposes of brick-making, without having to depend upon costly material brought over from other countries. Among such deposits implied may be mentioned those of bauxite, serpentine, steatite, limestone, dolomite, and magnesian limestone, although their successful application at high temperatures involves many problems which can only be solved by systematic research in co-operation with industry.

In blast-furnaces and cupolas chemical changes are involved in fluxation by actual contact with the semi-fused charges and the liquid slag, in the for- 
mation of scar, and as a possible result of the crystallization of volatilized compounds. To resist these influences the composition and texture of the bricks must be adjusted accordingly. With respect to the former it is especially important to have bricks free from oxide of iron if the formation of scar is to be prevented.

In addition to these destructive forces, which act chemically, there are others whose action is mechanical or physical in nature, and which, varying from point to point in different furnaces, occasionally become of first importance. Such are abrasion, differential movements, and permeability. Acting alone and in moderation the effects produced would not be very pronounced unless assisted by fluxation. Abrasion is probably only of moment in the shafts of blast-furnaces and cupolas. In the first it is considerably assisted by the formation of friable "scar," and in the second by careless charging. Differential movements, besides leading to general disintegration, tend to open up cracks and joints for the entrance of corrosive slags and vapours. The first become more important when assisted by gravity, as in the roof of an open-hearth furnace ; the second, in those places like the hearths of blastfurnaces, cupolas, and open-hearth furnaces, and in the case of regenerator chequer-works, where the bricks are directly exposed to liquid slag. The existence of any degree of permeability also assists fluxation in precisely the same way.

Furthermore, there are other factors having a more general application which are capable of being brought more directly under control of the steel manufacturer, viz. workmanship, regulation of the temperature during the first heat, and the careful adjustment of all tie-rods. The joints being lines of weakness, every care should be taken to make them as inconspicuous as possible, but in spite of every effort this is generally unattainable, because of the great variation in shape and size which exists amongst firebricks of every description. This variation is at the root of many evils, for besides rendering the brickwork more susceptible to destruction, it considerably increases the cost of erection, due to loss of time and wastage of bricks. Very often this irregularity is due to the friable nature of the bricks, as in the case of those rich in silica. During transit and handling they become rounded at the corners, and chipped and fractured often to a serious extent.

Below is given a list of papers and articles dealing with various aspects of refractory materials as they concern the iron and steel industries. Within each section they are arranged, as far as possible, in order of publication.

\section{B I B L I O G R A P H Y.}

\section{Physical Properties.}

\section{Conductivity.}

H. Steger: "Conductivity and Porosity," Stahl und Eisen, xxvii., pp. I697-9.

H. MeHner: Chemiker Zeitung, xxxi., p. I23o.

S. Wolagdine: "Conductivity, Porosity, and Permeability," Revue de Métallurgie, Mémoires, vi., pp. 767-806.

H. HERING : Electrochem. and Met. Ind., vii., pp. I I-I4.

J. K. Clement and W. L. Egy: Iron Trade Review, xlvi., pp. 821-3; Met. and Chem. Eng., x., pp. 286-7.

C. Hering, Mct. and Chem. Eng., ix., pp. $65^{2-4}$; ibid., x., pp. $40-4$.

S. M. Marshall : Met. and Chem. Eng., xii. (I9I4), p. 74.

E. F. Northrup : Met. and Chem. Eng., xii. (19r4), pp. 125-8. 


\section{DETERIORATION OF REFRACTORY MATERIALS}

II. Crushing Strength.

The Engineer, ci., p. 470 .

M. GRAY : Mitt. aus dem kgl. Materialpriifungsamt, xxviii., pp. 23-40.

A. V. Bleininger and G. H. Brown: Trans. Am. Cer. Soc., xiii., pp. $210-25$.

G. H. Brown : Trans. Am. Cer. Soc., March r9r3.

R. BANES : Tonindustrie Zeitung, May 1913, p. $73^{6}$.

\section{Softening Point.}

W. C. Heraeus : Zeit.f. angewandte Chemie, xviii., pp. 49-53.

T. Holgate : Engineering, lxxxv., pp. 235-8.

C. W. Kanolt : Iron and Coal Trades Review, lxxxv., p. 309 .

\section{Dilatation.}

J. W. Mellor: Iron and Coal Trades Revier, lxxxii., p. IO45.

J. M. Organ: Trans. Am. Cer. Soc., xiii., pp. 602-1 I ; Iron and Coal Trades Review, lxxxvii., p. 487.

\section{Various.}

F. T. HAVARD: Refractories and Furnaces, McGraw-Hill Co. (I9I2).

J. W. Mellor: Clay and Pottery Industries, Griffin \& Co. (I9r4).

H. B. Cronshaw : Iron and Steel Inst., Carnegie Sch. Mem., vii. (I916), pp. $\mathrm{r} 8-38$ and $\mathrm{r} 72-94$.

\section{REFRACTORINESS.}

P. Longmuir: Iron and Coal Trades Review, lxxii. (I906), pp. I2 I-2.

A. F. Greaves-Walker:: Iron Trade Review, August 23, r9o6, pp. I7-21.

A. V. Bleininger: Industrial World (I9og), pp. 70-2.

L. Baraduc-Muller : Revue de Métallurgie, Mémoires, vi., 700-29.

G. RIGG: Met. and Chem. Eng., viii., pp. 237-8 and 523-5; Foundry Trade Fournal, xii., pp. 374-6.

R. LEssing: Mech. Engineer, xxvi., pp. 847-8.

P. Windzus: Met. and Chem. Eng., x. (I912), p. 662.

P. Windzus : Tonindustrie Zeitung, xxxvi., p. 1205.

F. T. Havard: Refractories and Furnaces (1912), McGraw-Hill Co.

W. Stout : Trans. Am. Cer. Soc., March I9I3.

R. WALlaCH : Comptes Rendus, clvii. (I9I3), pp. 48-50.

F. WERniche: Stahl und Eisen, xxxiii. (r9r3), pp. 235-8.

G. RigG : Fourn. Ind. and Eng. Chem., v. (I9r3), pp. 549-54.

J. W. Mellor: Clay and Pottery Industries (I9I4), Griffin \& Co.

\section{STANDARDIZATION.}

Engineering, lxxxvii. (1909), p. I67.

Fournal of Gas Lighting, Ir4 (I9I I), pp. 843-5 ; Ir8 (I9I2), pp. 828-9.

F. T. HAVARD : Refractories and Furnaces (1912), McGraw-Hill Co.

Riehlé Road Materials Testing Machine, Catalogue "K." 


\section{IN THE IRON AND STEEL INDUSTRIES}

\section{Open-hearth Furnaces.}

B. Osann : Stahl und Eisen, xxiii., pp. 823-9; Met. and Chem. Eng., viii., pp. 106-7.

V. Groum-Grimails: Fourn. Russian Met. Soc., No. I (r9Io).

C. Canavis : Stahl und Eisen, xxxi., pp. I245-8.

O. LANGE : Stahl und Eisen, xxxii., pp. I729-37.

H. B. Cronshaw: Iron and Steel Inst., Carnegic Sch. Mem., vii. (I9I6), pp. $18-38$, and pp. $172-94$.

\section{Blast-FURNACES.}

Iron and Steel Inst. Fourn. (r89o), ii., p. 506 ; (189r), ii., p. 240.

C. Heucken, Tonindustrie Zeitung (r9or), pp. 1659-60.

JоснUм : Stahl und Eisen, xxiii., p. $42 \mathrm{I}$.

V. Henrion: Bulletin Technologique (1904), pp. 443-51.

T. Ludwig: Stahl und Eisen, xxv., pp. 870-2.

B. Osann : Stahl und Eisen, xxvii., pp. I491-6 ; ibid., pp. I529-36.

T. Turner: The Metallurgy of Iron (1908), Griffin \& Co.

V. Peters : Iron Age, lxxxii. (1909), pp. I074-6; lxxxiii. (1909), 1336-7.

H. Diтz: Stahl und Eisen, xxxii. (1912), pp. 1659-63.

C. GEIGER: Stahl und Eisen, xxxii. (rgr2), pp. r685-9o.

P. ANGLÈs D'AURIAC: Iron and Steel Inst. Fourn., i. (I9I2).

H. KINDER: Stahl und Eisen, xxxii., pp. $23^{\mathrm{I}-2 .}$

F. T. HAVARD: Refractories and Furnaces (rgr2), Griffin \& Co.

H. W. Croft : Year Book Am. Iron and Steel Inst. (1913), pp. 349-59.

A. N. DieHL: Year Book Am. Iron and Steel Inst. (19r3), pp. 360-6.

H. B. Cronshaw: Iron and Steel Inst., Carnegie Sch. Mem., vii. (Igr6), pp. I72-94.

\section{Coke Ovens.}

J. R. CAmpbell: Mines and Minerals, xxviii., pp. 457-9.

R. RIGG: Iron and Coal Trades Review, 1xxxi., pp. I34-6 ; lxxxvii. (1913), p. 487 .

\section{HOT-BLAST STOVES,}

A. F. Greaves-Walker: Iron Trade Review, August 23, I906, pp. I7-21.

B. Osann: Stahl und Eisen, xxix., pp. 1060-5, 1107-12, I147-51; xxx. pp. $1275^{-80}$.

W. A. Stanton : Iron Age, lxxvii., pp. 518-i9.

F. T. HAvard: Refractories and Furnaces (1912), Griffin \& Co.

A. N. Dienl: Year Book Am. Iron and Steel Inst. (19I3). 